\title{
THE INFLUENCE OF DOSAGE AND PRODUCTION PROCESS ON THE PHYSICAL AND MECHANICAL PROPERTIES OF AIR LIME MORTARS
}

\author{
L. Garijo ${ }^{1, *}$, X. X. Zhang ${ }^{2}$, G. Ruiz ${ }^{1}$, J. J. Ortega ${ }^{1}$ \\ ${ }^{1}$ School of Civil Engineering in Ciudad Real, University of Castilla-La Mancha, \\ Ciudad Real, Spain - (Lucia.Garijo; Gonzalo.Ruiz; JoseJoaquin.Ortega)@uclm.es \\ ${ }^{2}$ School of Mining and Industrial Engineering of Almaden, University of Castilla-La Mancha, Almaden, \\ Ciudad Real, Spain - Xiaoxin.Zhang@uclm.es
}

Commission II - WG II/8

KEY WORDS: Air lime mortars, Fabrication process, Dosage methodology, Physical properties, Mechanical properties.

\begin{abstract}
:
This paper studies the influence of five different factors affecting the dosage and production process of seven types of air lime mortars on their physical and mechanical properties. Such factors comprise the water/lime ratio, the aggregate type and size, the material of the mold and the curing conditions. Moreover, some physical and mechanical properties, not usually measured on air lime mortars, are obtained, such as open porosity, splitting tensile strength, fracture energy and elastic modulus measured through prisms. The results show that under the three different water/lime ratios tested, the material experiences a structural weakening. Ambient curing conditions were more favorable for air lime mortars than high humid ones. Moreover, it is observed that fabrication with wooden molds provided higher mechanical properties as they absorbed the free water, although this effect was probably local. Air lime mortar with an aggregate size of $2 \mathrm{~mm}$ had lower consistency in a fresh state as finer sands were more water demanding and the mechanical properties of this mortar were slightly lower than those of mortar with aggregate sizes of $0 / 4 \mathrm{~mm}$. Furthermore, using limestone aggregates improved the continuity between the lime and the matrix. This fact resulted in higher mechanical properties of the mortars with limestone aggregates in comparison to those with river sand when maintaining the same water/lime ratios. This study can suppose a further step in the improvement of the dosage methodology of air lime mortars.
\end{abstract}

\section{INTRODUCTION}

The dosage methodology of lime mortars is often based on the rules given by traditional treatises such as the ones written by Vitruvius (Bails, 1973). They establish that the appropriate lime/aggregate ratio for restoration purposes could be 1:3. More recently, other researchers have studied how various factors of the dosage methodology of lime mortars affect their mechanical properties, especially flexural and compressive strengths (Lanas et al., 2003; Santos et al., 2018; Veiga, 2017). However, it is often found that the amount of water used for the mortars fabricated is not always indicated nor the density of the raw materials, which makes the dosage process of said materials more difficult. Furthermore, there is a need for quantifying how these dosage factors affect advanced mechanical properties on lime mortars that are not so often measured. They are, for instance, the splitting tensile strength and fracture energy. Such properties are important to define the ductility and the fracture properties of the material.

This research forms part of a $\mathrm{PhD}$ thesis. The main purpose is to study the influence of various dosage factors of air lime mortars, such as the water/lime ratio, the material of the mold, the aggregate size and type, and the curing conditions on their physical and mechanical properties. Among the physical properties, it was measured the apparent density of the mortars, the consistency, the water retention capacity in a fresh state, while the open porosity, and capillary water absorption capacity in a hardened state. Among the mechanical properties, it was measured the flexural and compressive strengths as it is the common practice, but also the splitting tensile strength, the fracture energy and the elastic modulus from prisms. The results provide an advanced physical and mechanical characterization of seven air lime mortars under the influence of various factors to improve the dosage methodology of the material. From said results, further relationships could be established in a future work among the various properties measured, which will contribute to the enhancement of the dosage methodology.

\section{EXPERIMENTAL PROCEDURE}

\subsection{Fabrication of the air lime mortars}

Seven air lime mortars were fabricated with an air lime of class CL 90-S according to te standard EN 459-1 (BS EN 459-1, 2015). Such lime was provided by "Calcasa, Calcinor" (Spain) and it presented a bulk density of $490 \mathrm{~kg} / \mathrm{m}^{3}$. The lime/aggregate ratio adopted for the seven mortars was $1: 3$ by volume according to the recommendations for mortars for restoration purposes (Moropoulou et al., 2002; Bails, 1973). For the fabrication of the mortars, the following procedure was followed. First, a benchmark mortar was prepared. It presented a water/lime ratio of 0.9 , which provided plastic consistency (between $140 \mathrm{~mm}$ and $200 \mathrm{~mm}$ ), and crushed limestone aggregate with maximum grain size of $4 \mathrm{~mm}$. It was cast in metallic molds and it was cured for five initial days inside the humid chamber (RH: $97 \pm 0.5 \%, 20 \pm 0.5^{\circ} \mathrm{C}$ ) and the rest under the ambient laboratory conditions (RH: $52 \pm 12 \%, 22$ $\pm 3^{\circ} \mathrm{C}$ ) until day 56 . The rest of the mortars were prepared by varying one aspect of this benchmark one, see Table 1 . Then,

\footnotetext{
* Corresponding author
} 
the two following mortars were obtained by adopting corresponding water/lime ratios of 0.8 and 1.1 , obtaining dry $(<140 \mathrm{~mm})$ and fluid $(>200 \mathrm{~mm})$ consistencies, respectively. The next mortar was obtained by using the wooden molds instead of the metallic ones; another by using the same aggregate but with maximum grain size of $2 \mathrm{~mm}$; and another with river sand. Finally, the last mortar was obtained by curing it the entire time inside the humid chamber. The mixing process was performed according to EN 1015-2 (BS EN 1015-2, 1998/A1:2006). In total, 18 prismatic specimens (40 x 40 x 160 $\mathrm{mm}^{3}$ ) were fabricated for each type of mortar.

\subsection{Test procedures}

2.2.1 Tests in a fresh state: Such tests comprise the ones to obtain the bulk density of the mortar in a fresh state according to EN 1015-6 (BS EN 1015-6, 1998/A1:2006), the consistency according to the flow-table tests (EN 1015-3 (BS EN 1015-3, 1999/A2:2006) and EN 1015-6 (BS EN 1015-6, 1998/A1:2006)) and the water-retention capacity of the mortar by following the standard EN 459-2 (BS EN 459-2, 2010). More detail information on the procedures to perform said tests can be found in the thesis by Garijo (Garijo, 2019).

2.2.2 Tests in a hardened state: All these tests were performed in a hardened state at the age of 56 days. They comprise three physical tests; such as the one to measure the bulk density of the specimens by dividing the mass into their volume, the capillary water absorption according to EN 1015-18 (BS EN 1015-18, 2002) and the open porosity through hydrostatic methods by adapting the procedure for concrete, UNE 83980 (UNE 83980, 2014), to air lime mortars. Furthermore, mechanical tests were performed at the same age. They comprise the tests to obtain the flexural, compressive and splitting tensile strengths, the fracture energy and the elastic modulus.

The flexural tests were performed on three prismatic specimens measuring $40 \times 40 \times 160 \mathrm{~mm}^{3}$, according to EN 1015-11 (BS EN 1015-11, 1999/A1:2006). By following the same standard, the compressive tests were performed on the remaining six halves of the prisms from the previous tests in bending.

The splitting tensile tests was performed by adapting the standard EN 12390-6 (BS EN 12390-6, 2009) for concrete to lime mortars. The tests were performed on the remaining four halve prisms from the three-point bending tests to obtain the fracture energy (Figure 1a).

The fracture energy was obtained by three-point bending tests according to the RILEM (RILEM, 1985) recommendations and the improvements of Planas, Guinea and Elices (Planas et al., 1992; Guinea et al., 1992; Elices et al., 1992) on four prismatic specimens $\left(40 \times 40 \times 160 \mathrm{~mm}^{3}\right)$ with a central notch (Figure 1b). Said improvements consist in making the corresponding corrections in the tail of the load-displacement curve to estimate the unmeasured work.

From the previous three-point bending test, it was also possible to measure the elastic modulus. For the purpose, an extensometer (strain gauge extensometer Instron 2620) was affixed to the lower surface of the specimen to get the crackmouth opening displacement (CMOD) (Figure 1b). Then, the compliance of the initial branch of the load-CMOD curve was obtained and from it, the elastic modulus could be estimated by applying the equation given in the work by Garijo, Zhang, Ruiz et al. for natural hydraulic lime mortars (Garijo et al., 2018).
More detail information about the description of the previous mechanical tests can be found in (Garijo et al., 2018; Garijo, 2019; Garijo et al., 2017, 2020, 2019).

\section{RESULTS AND DISCUSSION}

The results of the tests in a fresh state are shown in Table 2, while the ones in a hardened state are shown in Figure 2. The influence of various dosage factors is analyzed as follows.

\subsection{Influence of the water/lime ratio}

It was studied through three mortars: the benchmark and the ones with corresponding water/lime ratios of 0.8 and 1.1 . From the results in a fresh state (Table 2), it is observed that higher water/lime ratios provide higher consistency by flow table test. Thus, it is $140-150 \mathrm{~mm}, 120-125 \mathrm{~mm}$, and $210-215$ $\mathrm{mm}$, respectively, for mortars with water/lime ratios of 0.9 , 0.8 and 1.1 .

However, the apparent density and the water/retention capacity of the fresh mortars are decreased with an increased in the water/lime ratio. Thus, their values can vary from $2290 \mathrm{~kg} / \mathrm{m}^{3}$ and $90.9 \%$ to $2160 \mathrm{~kg} / \mathrm{m}^{3}$ and $75.3 \%$, respectively, when comparing mortars with corresponding water/lime ratios of 0.8 and 1.1. Such results are logical: mortars with higher water content are less denser and present a lower capacity to retain water in a fresh state.

As for the properties in a hardened state, it is observed that higher water/lime ratios produce a weakening of the structure of the material by increasing the open porosity (Figure 2c). Then, with an increase in the open porosity, the capillary water absorption coefficient of the mortar also increases. Thus, it is $1.15 \mathrm{~kg} /\left(\mathrm{m}^{2} \mathrm{~min}^{0.5}\right), 1.27 \mathrm{~kg} /\left(\mathrm{m}^{2} \mathrm{~min}^{0.5}\right)$ and 1.38 $\mathrm{kg} /\left(\mathrm{m}^{2} \mathrm{~min}^{0.5}\right)$, respectively for mortars with water/lime ratios of $0.8,0.9$ and 1.1. This means that mortars with higher water/lime ratios are more prone to absorb water by capillarity and therefore, the risk of efflorescences appearance is also higher. As for the mechanical properties, it is also observed that higher water/lime ratios produce a weakening of them. In such a way, the compressive strength of mortars with water/lime ratios of 0.8 and 1.1 varies from $1.49 \mathrm{MPa}$ to 0.64 $\mathrm{MPa}$, while the fracture energy changes from $4.5 \mathrm{~N} / \mathrm{m}$ to 2.8 $\mathrm{N} / \mathrm{m}$, (Figures $2 \mathrm{e}$ and $2 \mathrm{~g}$ )

\subsection{Influence of the material of the mold}

It was studied through the benchmark mortar, cured inside the metallic molds, and another with the same properties in a fresh state that was cured inside the wooden molds. The purpose of this analysis was to reproduce the effect of wet bricks in masonry structures. From the results in a hardened state, it is observed that the open porosity, (Figure 2c), and the capillary water absorption coefficient, (Figure 2b), are higher for the mortar cured inside the wooden molds. The same happens with the mechanical properties, (Figures $2 \mathrm{~d}$ and $2 \mathrm{f}$ ). This could be because the wooden molds absorb the excess of water from the mortar and this results in a non-homogeneous material. This would explain that the core of the specimen is harder than in the benchmark mortar, which would provide higher mechanical properties. However, its surface is wetter, resulting in higher open porosity and capillary water absorption coefficient. The fracture energy and the elastic modulus from prisms, (Figures $2 \mathrm{~g}$ and $2 \mathrm{~h}$ ) could not be measured on the mortar with wooden molds because the specimens were broken just in the demolding process (Garijo et al., 2018; Garijo, 2019). 


\begin{tabular}{|l|c|c|c|c|c|}
\hline Mortar composition & $\begin{array}{c}\text { Water/lime ratio } \\
\text { (by volume) }\end{array}$ & Type of aggregate & $\begin{array}{c}\text { Maximum } \\
\text { grain size (mm) }\end{array}$ & Material of the mold & Curing conditions \\
\hline Benchmark & 0.9 & Crushed limestone & 4 & Metallic & 7 days in HC and 49 in AC \\
Water/lime 0.8 & 0.8 & Crushed limestone & 4 & Metallic & 7 days in HC and 49 in AC \\
Water/lime 1.1 & 1.1 & Crushed limestone & 4 & Metallic & 7 days in HC and 49 in AC \\
Wooden mold & 0.9 & Crushed limestone & 4 & Wooden & 7 days in HC and 49 in AC \\
Aggregate 0/2 mm & 0.9 & Crushed limestone & 2 & Metallic & 7 days in HC and 49 in AC \\
River sand & 0.9 & River sand & 4 & Metallic & 7 days in HC and 49 in AC \\
Curing conditions & 0.9 & Crushed limestone & 4 & Metallic & 56 in HC \\
\hline
\end{tabular}

Note. HC: Humid chamber (RH: $97 \pm 0.5 \%, 20 \pm 0.5^{\circ} \mathrm{C}$ ), AC: Ambient laboratory conditions (RH: $52 \pm 12 \%, 22 \pm 3^{\circ} \mathrm{C}$ ).

Table 1. Characteristics of the seven mortar compositions.
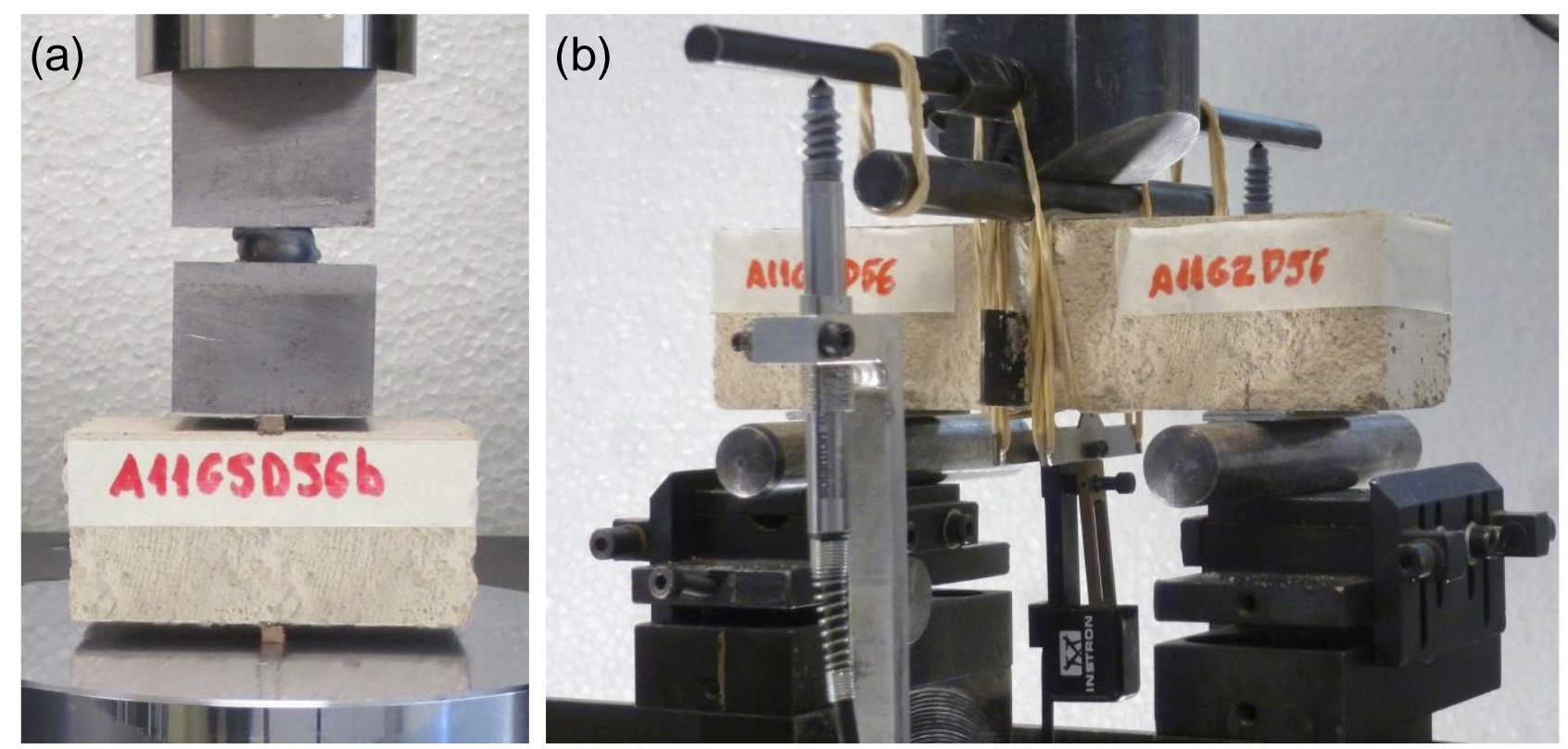

Figure 1. Tests set-up for: (a) splitting tensile strength, (b) fracture energy and elastic modulus.

\begin{tabular}{|l|c|c|c|c|c|}
\hline & \multicolumn{5}{|c|}{ Mortars tested } \\
\hline Properties & Benchmark & Water/lime:0.8 & Water/lime:1.1 & Maximum grain size: 2 mm & River sand \\
\hline Consistency (mm) & $140-150$ & $120-125$ & $210-215$ & $120-125$ & $150-155$ \\
Category of consistency & Plastic & Dry & Fluid & Dry & Plastic \\
Apparent density $\left(\mathrm{kg} / \mathrm{m}^{3}\right)$ & 2230 & 2290 & 2160 & 2230 & 2060 \\
Water retention $(\%)$ & 84.2 & 90.9 & 75.3 & 84.3 & 83.1 \\
\hline
\end{tabular}

Table 2. Properties of air lime mortars in a fresh state. 

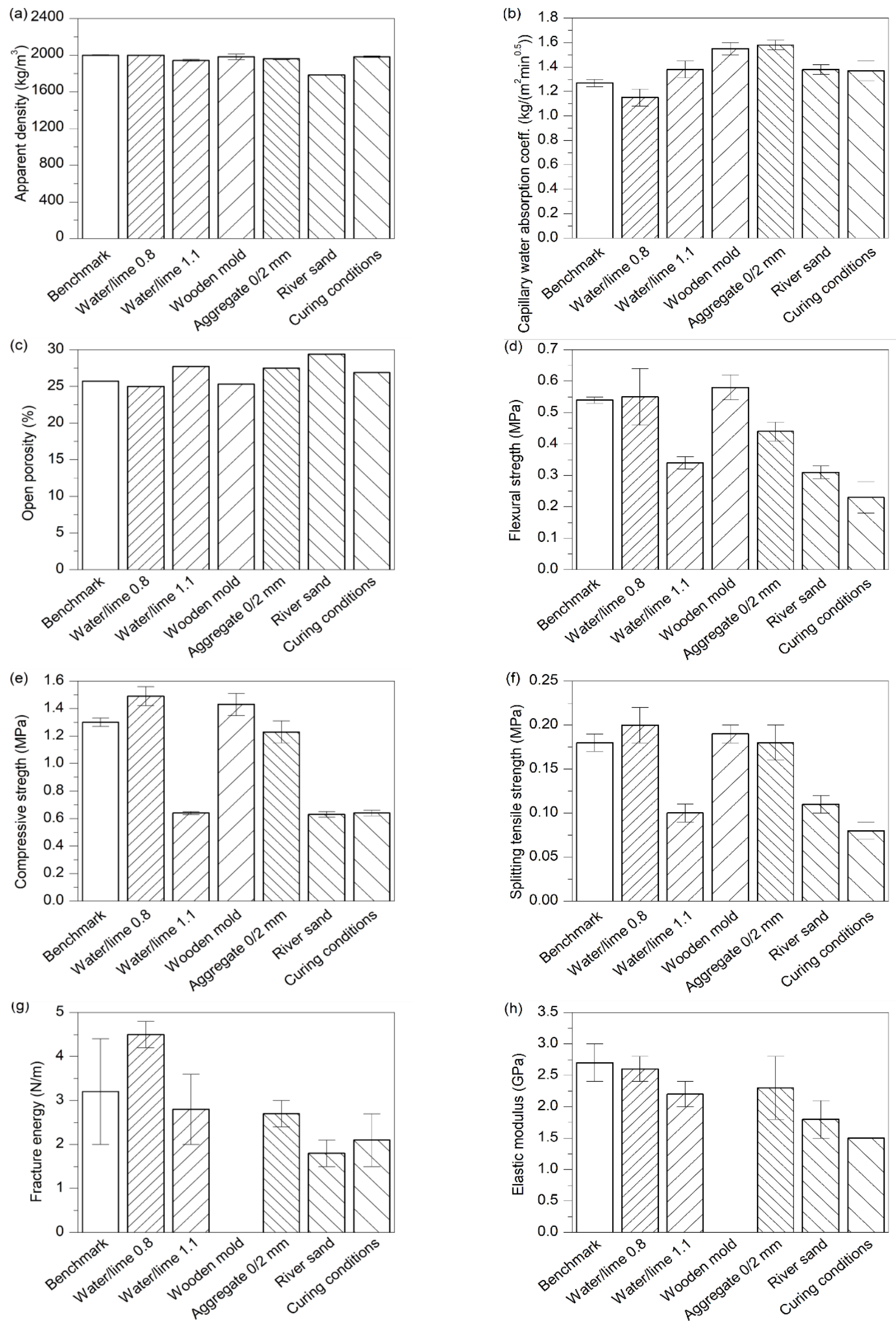

Figure 2. Properties of air lime mortars in a hardened state: (a) apparent density, (b) capillary water absorption coefficient, (c) open porosity, (d) flexural strength, (e) compressive strength, (f) splitting tensile strength, (g) fracture energy, and (h) elastic modulus. 


\subsection{Influence of the maximum aggregate size}

It was analyzed by comparing the benchmark mortar, with a maximum grain size of $4 \mathrm{~mm}$, with the one presenting the same aggregate but with a maximum grain size of $2 \mathrm{~mm}$. In a fresh state (Table 2), it is observed that the mortar with lower size of the aggregates is more water demanding and its resulting consistency is drier when the water/lime ratio is kept constant $(120-125 \mathrm{~mm}$ against $140-150 \mathrm{~mm}$ of the benchmark mortar). Their apparent densities and water retention capacities are very similar.

In a hardened state, it is observed that mortar with a lower grain size presents higher open porosity (27.5\% against $25.7 \%$ ), (Figure 2c), in comparison to the benchmark mortar. However, their mechanical properties are very similar, (Figures $2 \mathrm{~d}$ and $2 \mathrm{~h}$ ). In this case, the effect of using smaller aggregate size, which would normally provide lower mechanical properties (Stefanidou, Papayianni, 2005), is counteracted with the fact that the mortar presents drier consistency for the same water/lime ratio (Garijo, 2019).

\subsection{Influence of the type and shape of aggregates}

The properties of the benchmark mortar, fabricated with a crushed limestone aggregate, are compared with those of the mortar fabricated with river sand. In a fresh state, it is observed that the latter presents higher consistency (150-155 mm against 140-150 mm, see Table 2) when using the same water/lime ratio. Consequently, its apparent density and water retention capacity are lower than in the benchmark mortar.

In a hardened state, the mortar with river sand presents higher open porosity $(29.4 \%$ against $25.7 \%$, see Figure $2 \mathrm{c}$ ), and capillary water absorption coefficient $\left(1.38 \mathrm{~kg} /\left(\mathrm{m}^{2} \mathrm{~min}^{0.5}\right)\right.$ against $1.38 \mathrm{~kg} /\left(\mathrm{m}^{2} \mathrm{~min}^{0.5}\right)$, (Figure $2 \mathrm{~b}$ ). As for the mechanical properties, it is observed that they are lower for the mortar with river sand. For example, its compressive strength and fracture energy decrease by around $50 \%$ and $40 \%$, respectively, when compared with the benchmark mortar. This could be because the interlocking between the round particles of the river sand is not so effective as the one between the particles of the crushed limestone aggregate. Furthermore, according to other researchers (Santos et al., 2018; Lanas, Alvarez, 2003), the limestone nature of the second aggregates improves the crystallographic continuity with the lime.

\subsection{Influence of the curing conditions}

It was assessed by comparing the properties of the benchmark mortar, cured for five initial days inside the humid chamber (RH: $97 \pm 0.5 \%, 20 \pm 0.5^{\circ} \mathrm{C}$ ) and the rest under ambient laboratory conditions (RH: $52 \pm 12 \%, 22 \pm 3^{\circ} \mathrm{C}$ ), with the mortar cured the entire time inside the humid chamber.

The same procedure was followed to fabricate both mortars, so their properties in a fresh state are the same. In a hardened state, the open porosity and capillary water absorption coefficient are slightly higher for the mortar cured the entire time inside the humid chamber $\left(26.9 \%\right.$ and $1.37 \mathrm{~kg} /\left(\mathrm{m}^{2} \mathrm{~min}^{0.5}\right)$, respectively, against $25.7 \%$ and $1.27 \mathrm{~kg} /\left(\mathrm{m}^{2} \mathrm{~min}^{0.5}\right)$, (Figures $2 \mathrm{c}$ and $2 \mathrm{~b}$ ). However, the mechanical properties are significantly lower for this mortar, (Figures $2 \mathrm{~d}$ and $2 \mathrm{~h}$ ). For example, its compressive and splitting tensile strengths decrease by around $66 \%$ and 55\%, respectively when compared with those of the benchmark mortar. This is in agreement with other researchers (Saetta et al., 1995; Lanas et al., 2006) that found that medium relative humidity conditions, between $40 \%$ and $80 \%$, favoured the carbonation reaction of air lime mortars.

\section{CONCLUSIONS}

In this research, the influence of five dosage factors on physical and mechanical properties of seven air lime mortars is studied. Such factors comprise the water/lime ratio, the material of the mold, the aggregate size and type, and the curing conditions. Among the physical properties, the apparent density, the consistency and the water retention capacity were measured in a fresh state; while the apparent density, the capillary water absorption coefficient, the open porosity, and some advanced mechanical ones, such as the flexural, compressive and splitting tensile strengths, the fracture energy and the elastic modulus in a hardened state. The results show that a compromise must be reached when selecting the water/lime ratio to reach appropriate consistency and sufficient mechanical properties. Furthermore, the use of wooden molds, which simulates the wet bricks of masonry structures, provides a mortar with higher mechanical properties than the one cured inside the metallic molds but with higher porosity. Aggregates with lower grain size (maximum of $2 \mathrm{~mm}$ ) provide similar mechanical properties as the ones with maximum grain size of $4 \mathrm{~mm}$; while crushed limestone aggregates improve the cohesion among the particles inside the mortar and increase the crystallographic continuity between them and the lime. Finally, it was confirmed that ambient laboratory conditions favour the carbonation process of air lime mortars in comparison to humid curing conditions. Such results can be useful to improve the dosage methodology of air lime mortars and could be the bases of future relationships of the measured properties to contribute to said enhancement.

\section{ACKNOWLEDGEMENTS}

We thank funding from the Ministerio de Ciencia, Innovación y Universidades, Spain, under projects BIA2015-68678-C2-1-R and RTC-2017-6736-3, from the Junta de Comunidades de Castilla-La Mancha (JCCM) and Fondo Europeo de Desarrollo Regional, Spain, under grant PEII-2014-016-P.

The first and the last authors appreciate the financial support from the corresponding scholarships FPU014/05186 from the Ministerio de Educación, Cultura y Deporte, Spain, and 2016/12998 from JCCM, Spain.

Advice on the fabrication of the lime mortars from Prof. Pere Roca, of the Polytechnic University of Catalonia, is also very much appreciated.

\section{REFERENCES}

Bails, B., 1973. Diccionario de Arquitectura Civil. Obra póstuma. Colegio de Aparejadores y Arquitectos Técnicos de Asturias, Oviedo, Spain.

BS EN 1015-11, 1999/A1:2006. Methods of test for mortar for masonry - Part 11: Determination of flexural and compressive strength of hardened mortar.

BS EN 1015-18, 2002. Methods of test for mortar for masonry - Part 18: Determination of water absorption coefficient due to capillary action of hardened mortar.

BS EN 1015-2, 1998/A1:2006. Methods of test for mortar for masonry - Part 2: Bulk sampling of mortars and preparation of test mortars.

BS EN 1015-3, 1999/A2:2006. Methods of test for mortar for masonry - Part 3: Determination of consistence of fresh mortar (by flow table). 
BS EN 1015-6, 1998/A1:2006. Methods of test for mortar for masonry - Part 6: Determination of bulk density of fresh mortar.

BS EN 12390-6, 2009. Testing hardened concrete - Part 6: Tensile splitting strength of test specimens.

BS EN 459-1, 2015. Building lime - Part 1: Definitions, specifications and conformity criteria.

BS EN 459-2, 2010. Building lime - Part 2: Tests methods.

Elices, M., Guinea, G. V., Planas, J., 1992. Measurement of the fracture energy using three-point bend tests: Part 3-Influence of cutting the $P-\delta$ tail. Materials and Structures, 25(150), 327334.

Garijo, L., 2019. Advanced mechanical characterization of lime mortars and other materials of the civil and architectural patrimony. PhD thesis, Civil Engineering School of University of Castilla-La Mancha, http://hdl.handle.net/10578/23043.

Garijo, L., Zhang, X., Ruiz, G., Ortega, J. J., Yu, R. C., 2017. Advanced mechanical characterization of NHL mortars and cohesive simulation of their failure behavior. Construction and Building Materials, 153, 569-577.

Garijo, L., Zhang, X., Ruiz, G., Ortega, J., Yu, R. C., 2019. Mechanical Behavior of Natural Hydraulic Lime Mortars. Intech Open (ed.), Sustainable Construction and Building Materials, 1-20.

Garijo, L., Zhang, X. X., Ruiz, G., Ortega, J. J., 2020. Age effect on the mechanical properties of natural hydraulic and aerial lime mortars. Construction and Building Materials, 236, 117573 .

Garijo, L., Zhang, X. X., Ruiz, G., Ortega, J. J., Wu, Z., 2018. The effects of dosage and production process on the mechanical and physical properties of natural hydraulic lime mortars. Construction and Building Materials, 169, 325-334.

Guinea, G. V., Planas, J., Elices, M., 1992. Measurement of the fracture energy using three-point bend tests: Part 1-Influence of experimental procedures. Materials and Structures, 25(148), 212-218.

Lanas, J., Alvarez, J. I., 2003. Masonry repair lime-based mortars: Factors affecting the mechanical behavior. Cement and Concrete Research, 33(11), 1867-1876.

Lanas, J., Sirera, R., Alvarez, J. I., 2006. Study of the mechanical behavior of masonry repair lime-based mortars cured and exposed under different conditions. Cement and Concrete Research, 36(5), 961-970.

Moropoulou, A., Cakmak, A. S., Biscontin, G., Bakolas, A., Zendri, E., 2002. Advanced Byzantine cement based composites resisting earthquake stresses: the crushed brick/lime mortars of Justinian's Hagia Sophia. Construction and Building Materials, 16(8), 543-552.

Planas, J., Elices, M., Guinea, G. V., 1992. Measurement of the fracture energy using three-point bend tests: Part 2-Influence of bulk energy-dissipation. Materials and Structures, 25(149), 305-312.
RILEM, 1985. RILEM Committee on Fracture Mechanics of Concrete, Determination of the fracture energy of mortar and concrete by means of the three-point bend tests on notched beams, Draft recommendation, TC 50-FMC. Materials and Structures, 285-290.

Saetta, A. V., Schrefler, B. A., Vitaliani, R. V., 1995. 2-D Model for carbonation and moisture heat-flow in porous materials. Cement and Concrete Research, 25(8), 1703-1712.

Santos, A. R., Veiga, M. R., Silva, A. S., De Brito, J., Ignacio Alvarez, J., 2018. Evolution of the microstructure of lime based mortars and influence on the mechanical behaviour: The role of the aggregates. Construction and Building Materials, 187, 907922 .

Stefanidou, M., Papayianni, I., 2005. The role of aggregates on the structure and properties of lime mortars. Cement \& Concrete Composites, 27(9-10), 914-919.

UNE 83980, 2014. Concrete durability. Test methods. Determination of the water absorption, density and accessible porosity for water in concrete.

Veiga, R., 2017. Air lime mortars: What else do we need to know to apply them in conservation and rehabilitation interventions? A review. Construction and Building Materials, $157,132-140$. 